Article

\title{
Effects of Drought Stress on Some Agronomic and Morpho-Physiological Traits in Durum Wheat Genotypes
}

\author{
Alireza Pour-Aboughadareh ${ }^{1, * \mathbb{C}}$, Reza Mohammadi ${ }^{2}$, Alireza Etminan $^{3}$, Lia Shooshtari $^{4}$, \\ Neda Maleki-Tabrizi ${ }^{5}$ and Peter Poczai ${ }^{6, *(D)}$ \\ 1 Seed and Plant Improvement Institute, Agricultural Research, Education and Extension \\ Organization (AREEO), P.O. Box 3183964653, Karaj 47419, Iran \\ 2 Dryland Agricultural Research Institute, Sararood branch, Agricultural Research, Education and Extension \\ Organization (AREEO), Kermanshah 67146, Iran; r.mohammadi@areeo.ac.ir \\ 3 Department of Plant Breeding and Biotechnology, Kermanshah Branch, Islamic Azad University, \\ Kermanshah 67146, Iran; a.etminan@iauksh.ac.ir \\ 4 Department of Plant Breeding, Kermanshah Branch, Islamic Azad University, Kermanshah 67146, Iran; \\ L.shooshtari@iauksh.ac.ir \\ 5 Department of Agronomy and Plant Breeding, Faculty of Agricultural Science and Engineering, \\ University of Tehran, Tehran 15119-43943, Iran; n.malekitabrizi@gmail.com \\ 6 Botany Unit, Finnish Museum of Natural History, University of Helsinki, P.O. Box 7, \\ FI-00014 Helsinki, Finland \\ * Correspondence: a.poraboghadareh@ut.ac.ir (A.P.-A.); peter.poczai@helsinki.fi (P.P.)
}

Received: 22 June 2020; Accepted: 8 July 2020; Published: 13 July 2020

check for updates

\begin{abstract}
Durum wheat performance in the Mediterranean climate is limited when water scarcity occurs before and during anthesis. The present research was performed to determine the effect of drought stress on several physiological and agro-morphological traits in 17 durum wheat genotypes under two conditions (control and drought) over two years. The results of analysis of variance indicated that the various durum wheat genotypes responded differently to drought stress. Drought stress significantly reduced the grain filling period, plant height, peduncle length, number of spikes per plot, number of grains per spike, thousand grains weight, grain yield, biomass, and harvest index in all genotypes compared to the control condition. The heatmap-based correlation analysis indicated that grain yield was positively and significantly associated with phenological characters (days to heading, days to physiological maturity, and grain filling period), as well as number of spikes per plant, biomass, and harvest index under drought conditions. The yield-based drought and susceptible indices revealed that stress tolerance index (STI), geometric mean productivity (GMP), mean productivity (MP), and harmonic mean (HM) were positively and significantly correlated with grain yields in both conditions. Based on the average of the sum of ranks across all indices and a three-dimensional plot, two genotypes (G9 and G12) along with the control variety (G1) were identified as the most tolerant genotypes. Among the investigated genotypes, the new breeding genotype G12 showed a high drought tolerance and yield performance under both conditions. Hence, this genotype can be a candidate for further multi-years and locations test as recommended for cultivation under rainfed conditions in arid and semi-arid regions.
\end{abstract}

Keywords: drought stress; yield-based indices; average of sum of rank method (ASR); yield performance 


\section{Introduction}

Among cereal crops, durum wheat (Triticum durum Desf.) is widely cultivated in the Mediterranean region and other semi-arid areas of the world [1]. It represents an essential food source, as it provides carbohydrates, dietary proteins, fiber, calcium, zinc, fats, and energy [2]. Durum wheat is usually grown under rainfed conditions where fluctuations in precipitation have caused water scarcity to act as a major limiting factor for crop productivity, particularly when water deficit stress occurs during the flowering and grain filling period stages [3]. It is clear that plant survival and development in stressful environments-especially drought conditions-depend on its adaptive mechanisms and defense systems, such as nutrient and water uptake from the deep layers of soil, osmotic adjustment by the active accumulation of free amino acids, ions, sugars, and proline, biochemical activities, stomatal control of water loss, and phenological plasticity [4,5].

The pattern of biomass allocation is a key growth parameter of an adaptive strategy in plants, especially in drought conditions. It is strictly associated with the size and morphological construction of crop organs [6]. Studies of agro-morphological, biochemical, and physiological responses under rainfed conditions can advance our understanding of the ability of crops to respond and adapt to drought-prone environments. Several agro-morphological traits such as plant height, peduncle length, number of fertile tillers per plant, spike length, number of grains per spike, thousand grains weight, and even awn length not only affect stress tolerance to limited soil moisture in wheat, they also reveal how adaptive genotypes cope with drought via morphological changes [7]. Similar to other crops, the important physio-chemical responses and parameters for evaluating drought response in wheat include chlorophyll content, stomatal conductance, leaf water potential, photosynthetic rate, and transpiration rate [8].

Despite intensive durum wheat breeding programs in the last century, in-depth comprehension of the agronomic and morpho-physiological responses of wheat to drought stress is not available. Hence, agro-morphological assessments might be useful to improve the successive operations of wheat processing and transformation. In particular, the selection of cultivars resistant to drought stress and the adoption of correct agronomic treatments [9] might prevent problems and complications during essential operations of wheat milling and flour processing [10]. Moreover, the development, selection, and cultivation of durum wheat cultivars resistant to drought stress which do not need significant input of fertilizers might decrease carbon and water footprints, reducing environmental impacts [11]. Over a long period of selection and breeding of wheat by plant breeders, complex strategies involving agro-morphological traits along with physiological and biochemical mechanisms have been incorporated to cope with drought stress [12]. Hence, knowledge of the association between yield performance and these traits, as well as accurate estimations of stress tolerance in plant genetic material, can be used to improve the efficiency of breeding programs in diverse environments [13]. The objectives of the current study were to evaluate the 16 agronomic and morpho-physiological responses of 17 durum wheat genotypes exposed to drought stress and identify effective traits to facilitate a screening process in future durum wheat breeding programs that will lead to improved yield performance under rainfed conditions.

\section{Materials and Methods}

\subsection{Plant Materials and Experimental Layout}

The experiments were carried out in the Dryland Agricultural Research Sub-Institute (DARSI) of Iran (Sararood Station, Kermanshah, Iran, 34 $4^{\circ} 19^{\prime}$ N; $47^{\circ} 17^{\prime}$ E; 1351 m a.s.l.) A set of 16 durum wheat genotypes along with a bread wheat local check (Table 1) were investigated under irrigated (supplemental irrigation; two times irrigation from heading to mid-grain filling stages) and rainfed (hereon referred to as drought stress) conditions during two cropping seasons (2011-2012 and 2012-2013). The soil texture at the station was clay loam, and the average long-term annual precipitation is an estimated $425 \mathrm{~mm}$. For each experiment, a randomized complete block design with three replications 
was used. The plot size was $7.2 \mathrm{~m}^{2}$, which included 6 rows, each $6 \mathrm{~m}$ long, spaced $20 \mathrm{~cm}$ apart. The soil was supplemented with $50 \mathrm{~kg} \mathrm{~N} \mathrm{ha}^{-1}$ and $50 \mathrm{~kg} \mathrm{P}_{2} \mathrm{O}_{5} \mathrm{ha}^{-1}$.

Table 1. Code, name/pedigree and origin of tested durum wheat genotypes.

\begin{tabular}{cccc}
\hline Code & Pedigree & Name & Origin \\
\hline G1 & Saji & Check variety & Iran \\
G2 & Zardak & Old variety & Iran \\
G3 & Sardari & Bread wheat old variety & Iran \\
G4 & TOPDY_18/FOCHA_1//ALTAR 86 & Breeding line & Iran \\
G5 & RASCON_37/4/MAGH72/RUFO//ALG86 & Breeding line & Iran \\
G6 & M84859 & Breeding line & ICARDA \\
G7 & M141979 & Breeding line & ICARDA \\
G8 & M141982 & Breeding line & ICARDA \\
G9 & M141994 & Breeding line & ICARDA \\
G10 & M141995 & Breeding line & ICARDA \\
G11 & M142005 & Breeding line & ICARDA \\
G12 & M142017 & Breeding line & ICARDA \\
G13 & M142025 & Breeding line & ICARDA \\
G14 & M142038 & Breeding line & ICARDA \\
G15 & M142045 & Breeding line & ICARDA \\
G16 & M142069 & Breeding line & ICARDA \\
G17 & M142070 & Breeding line & ICARDA \\
\hline
\end{tabular}

\subsection{Physiological Assay}

The potential quantum efficiency of photosystem II (Fv/Fm), canopy temperature, relative chlorophyll content (SPAD reading), and stomatal conductance (SC; mmol m $\mathrm{m}^{-2}$ ) were taken on the flag leaf. The Fv/Fm measurements and canopy temperature were taken between 11:00 and 14:00, and between 12:00 and 14:00 using a portable Fluorometer (Optic-Science OS-30p, Hudson, NY, USA) and infrared thermometer (Model: E200IR, Germany), respectively. The SPAD index was measured for three flag leaves in each plot using the SPAD chlorophyll meter (Minolta Co. Ltd., Tokyo, Japan). SC was estimated from three random flag leaves in each plot using the leaf porometer (Decagon Devices, Inc., Pullman, WA, USA).

\subsection{Agro-Morphological Assay}

The following agronomic traits were evaluated: days to heading (DH), days to maturity (DM), grain filling period (GFP), plant height $(\mathrm{PH})$, peduncle length (PL; cm), flag leaf length (FL; $\mathrm{cm})$, number of spikes per plot (NSPP), spike length (SL; cm), number of grains per spike (NGPS), thousand grains weight (TGW; g), grain yield (GY; $g$ plot ${ }^{-1}$ ), biological biomass (Bio; $\mathrm{g} \mathrm{plot}{ }^{-1}$ ), and harvest index (HI; \%). All traits were measured based on five randomly selected samples of each genotype during different stages from development stage to maturity. Days to heading and maturity were recorded as number of days from planting until $50 \%$ of the heads and physiological maturity in a plot. Plant height was recorded from ground to the tip of the main spike at maturity. Length of flag leaf was measured from leaf sheath to the tip of leaf. Peduncle length was measured from the last node from the top of the plant to the rachis. The main spike length was measured excluding awns. Grain yield and biomass were calculated according to one meter square $\left(\mathrm{g} \mathrm{m}^{-2}\right)$ for each genotype, and then converted to $g$ plot $^{-1}$. Biomass was estimated from the above-ground tissues including the tillers per plant and spikes. Harvest index was calculated by dividing the grain yield by the biological yield.

\subsection{Statistical Analysis}

The combined analysis of variance (ANOVA) was performed using SAS software ver. 9.1 [14]. Pearson's correlation coefficients were calculated for each pair of traits per growth condition using XLSTAT software (Addisonsoft XLSTAT, Paris, French). Several susceptibility and tolerance indices, 
along with their ranks, were calculated using the iPASTIC toolkit [15]. Furthermore, the ranking method was used to identify the best genotypes according to the different measured indices following the methodology proposed by Ketata et al. [16]. Based on this approach, the average rank sum (ASR) for all indices was used as an indicator to select the best genotypes. Accordingly, the best performance of each trait received the lowest rank, hence the genotypes with the lowest ASR and standard deviation (SD) values were identified as the best genotypes.

\section{Results}

\subsection{Analysis of Variance, Range of Data, and Means Comparison}

The results of the combined analysis of variance (ANOVA) on grain yield and other measured traits indicated significant effects for year (except for PL, TGW, and Fv/Fm), stress (except for SL, FL and SC), and genotypes (TGW, SC, CT, Fv/Fm, and Bio). The interaction of year and stress effects was significant for all traits except SL, PE, FL, TGW, Fv/Fm, SC, and Bio. Moreover, the genotype and year interaction was significant for DH, DM, GFP, NSPP, SC, CT, GY, HI, and Bio, whereas the genotype and stress interaction was significant for DH, DM, GFP, PL, NGPS, NSPP, GY, and Bio. On the other hand, the three-way interaction between year, stress and genotype was only significant for DH, DM, and GFP traits (Table 2). The coefficient of variance (CV) ranged from 0.48 to $43.06 \%$; the highest value was observed for $\mathrm{Fv} / \mathrm{Fm}$ (43.06\%), followed by PE (32.69\%) and GY (26.56\%).

Table 2. Combined analysis of variance (ANOVA) for measured agronomic and morpho-physiological traits in tested durum wheat genotypes under control and drought conditions.

\begin{tabular}{|c|c|c|c|c|c|c|c|c|c|}
\hline Source of Variation & Year (Y) & Stress (S) & YS & Replication/SY & Genotype (G) & GY & GS & GSY & CV (0/) \\
\hline df & 1 & 1 & 1 & 8 & 16 & 16 & 16 & 16 & \\
\hline $\mathrm{DH}$ & ** & ** & $* *$ & Ns & ** & $* *$ & $* *$ & ** & 0.48 \\
\hline DM & $* *$ & $* *$ & $* *$ & Ns & $* *$ & $* *$ & $* *$ & $* *$ & 0.76 \\
\hline GFP & $* *$ & $* *$ & $* *$ & Ns & $* *$ & $* *$ & $* *$ & $* *$ & 4.04 \\
\hline PL & $* *$ & $* *$ & $* *$ & * & $* *$ & Ns & * & Ns & 15.89 \\
\hline PE & Ns & $* *$ & Ns & $* *$ & $* *$ & Ns & Ns & Ns & 32.69 \\
\hline FL & $* *$ & Ns & Ns & $*$ & $* *$ & Ns & Ns & Ns & 12.84 \\
\hline SL & $* *$ & Ns & Ns & Ns & $* *$ & Ns & Ns & Ns & 10.31 \\
\hline NSPP & $* *$ & $* *$ & $* *$ & $* *$ & $* *$ & Ns & * & Ns & 21.01 \\
\hline NGPS & $* *$ & $* *$ & $* *$ & Ns & $* *$ & Ns & $*$ & Ns & 19.55 \\
\hline TGW & Ns & $* *$ & Ns & Ns & Ns & Ns & Ns & Ns & 17.69 \\
\hline GY & $* *$ & $* *$ & * & $* *$ & $* *$ & $* *$ & * & Ns & 26.56 \\
\hline Bio & $* *$ & $* *$ & Ns & $* *$ & Ns & $* *$ & Ns & Ns & 21.89 \\
\hline $\mathrm{HI}$ & $* *$ & $* *$ & $*$ & Ns & $* *$ & * & $\mathrm{Ns}$ & Ns & 13.68 \\
\hline $\mathrm{Fv} / \mathrm{Fm}$ & Ns & * & Ns & Ns & Ns & Ns & $\mathrm{Ns}$ & Ns & 10.74 \\
\hline SC & $* *$ & Ns & Ns & $* *$ & Ns & Ns & Ns & Ns & 43.06 \\
\hline $\mathrm{CT}$ & * & $* *$ & $* *$ & $* *$ & Ns & $*$ & Ns & Ns & 3.96 \\
\hline
\end{tabular}

$\mathrm{Ns}^{*}$, and ${ }^{* *}$ indicate non-significant and significant at $5 \%$ and $1 \%$ levels of probability, respectively. DH: days to heading; DM: days to maturity; GFP: grain filling period; PL: plant height (cm); PE: peduncle length (cm); FL: flag leaf length $(\mathrm{cm})$; SL: spike length $(\mathrm{cm})$; NSPP: number of spike per plot; NGPS: number of grains per spike; TGW: thousand grains weight (g); GY: grain yield $\left(\mathrm{g} \mathrm{plot}^{-1}\right)$; Bio: biomass ( $\left.\mathrm{g} \mathrm{plot}^{-1}\right)$; HI: harvest index; Fv/Fm: maximum quantum yield of PSII; SC: stomatal conductance $\left(\mathrm{mmol} \mathrm{m}^{-2} \mathrm{~s}^{-1}\right)$; CT: canopy temperature $\left({ }^{\circ} \mathrm{C}\right)$.

Drought stress significantly decreased TGW, GY, PE, NGPS, HI, NSPP, PL, Bio, and GFP by $44.93 \%, 36.49 \%, 31.83 \%, 26.21 \%, 21.62 \%, 20.60 \%, 19.23 \%, 18.99 \%$, and $13.91 \%$ compared with the control condition. On the other hand, drought stress increased CT, Fv/Fm, DM, and FL across all investigated genotypes by $20.71 \%, 3.56 \%, 2.05 \%$, and $1.42 \%$ compared with the control condition (Table 2). The response of each genotype for the measured traits under control and drought conditions is shown in Table 3. Under the control condition, DH ranged from 214.83 to 219 days (mean 218), and genotypes G3, G6, and G8 showed a short time of spike appearance. Under the drought condition, $\mathrm{DH}$ varied between 213.67 and 217.67 days (mean 215), and most of the tested genotypes showed a similar pattern; G5, G10, and G15 had the highest values. There was low variability in days to maturity under both conditions; this trait varied between 170 and 176.67 days (average 173) under the control condition, and between 173.83 and 179.33 days (average $~ 176$ ) under the drought conditions. Under the 
control condition, genotypes G7, G10, and G12 were identified as the early-maturing genotypes; under drought condition, the early-maturing genotypes were G6, G7, and G8. The GFP indicated a low variability in both conditions. In the control, GFP ranged from 41.50 to 47.83 days (average $~ 45$ ), and the best genotypes were G4, G5, and G8. In the drought condition, this phonological trait varied between 35.17 and 41.50 days (average $~ 39$ ), and G6, G8, and G10 had the shortest grain filling period. The PL ranged from 24.47 to $33.28 \mathrm{~cm}$ (average $29.52 \mathrm{~cm}$ ) under the control condition, whereas in the drought condition it ranged from 16.86 to $26.53 \mathrm{~cm}$ (average $23.85 \mathrm{~cm}$ ). Under control conditions, G7, G8, and G16 showed the highest values for plant height; under drought, the highest plant heights were seen in G6, G12, and G14.

In the control condition, there was no significant difference among the tested genotypes in terms of $\mathrm{PE}$, while under drought conditions this trait varied between 3.97 and $11.83 \mathrm{~cm}$ (average $8.58 \mathrm{~cm}$ ). Therefore, the ideal genotypes with the highest peduncle length were G8, G16, and G17. The range of variability across all 17 tested durum genotypes for FL was limited in both growth conditions; it ranged from 12.95 to $17.97 \mathrm{~cm}$ (average $15.13 \mathrm{~cm}$ ) and from 12.69 to $16.94 \mathrm{~cm}$ (average $15.34 \mathrm{~cm}$ ) under control and drought conditions, respectively. The highest values for FL under the control condition were recorded in genotypes G2, G5, and G15; under drought condition, the highest values were seen in genotypes G2, G5, and G13 compared to other genotypes. Likewise, the range of variability for SL was limited, and it varied between 6.08 and $9.45 \mathrm{~cm}$ (average $6.94 \mathrm{~cm}$ ) and between 6.03 and $8 \mathrm{~cm}$ (average $6.93 \mathrm{~cm}$ ) under control and drought conditions, respectively. The longest spikes were observed in G3 and G8 (Table 2).

The NSPP indicated a high variability, ranging from 431.67 to 895.83 (average 576.23) under control conditions, and from 297.50 to 627.83 (average 457.52) under the drought condition. G3, G14, and G16 in the control and G2, G3, and G8 in the drought condition had the highest number of spikes per plants. The range of variability for NGPS was considerable-it spanned from 23.32 to 49.07 (average 42.27) and from 19.50 to 35.13 (average 31.19) under control and drought conditions, respectively. Genotypes G12, G16, and G17 in the control condition, and G1, G13, and G14 in the drought condition indicated the highest number of grains per spike. In the control condition, there was no significant difference among genotypes in terms of TGW, whereas under the drought condition genotypes responded to drought in different ways. Indeed, under the drought condition, TGW varied between 19.06 and 27.61 (average 24.05), and the highest values were recorded in G2, G4, and G6. The tested durum wheat genotypes in the present study revealed a high variability for GY. In the control condition, GY ranged from 463.77 to $888.57 \mathrm{~g} \mathrm{plot}^{-1}$ (average $721.18 \mathrm{~g} \mathrm{plot}^{-1}$ ); genotypes G1, G10, and G16 indicated the highest grain yield. Under the drought condition, GY ranged from 356.17 to $546.63 \mathrm{~g} \mathrm{plot}^{-1}$ (average $458 \mathrm{~g} \mathrm{plot}^{-1}$ ); G1, G9, and G12 were identified as the highest yield genotypes (Table 2). There was a high rate of variation in Bio across the 17 durum wheat genotypes in the control condition. Three genotypes (G1, G14, and G16) showed the highest amount of dry biomass per plot. Furthermore, HI ranged from 27.75 to $37.36 \%$ (average $33.39 \%$ ), and G1, G10, and G17 were identified as the best genotypes. However, there were no significant differences in Bio and HI among the tested genotypes under the drought condition. Furthermore, under both growth conditions there were no significant differences among the tested genotypes for $F v / F m$ and CT traits. Nevertheless, SC displayed a range of variability, which spanned from 25.79 to $58.19 \mathrm{mmol} \mathrm{m}^{-2} \mathrm{~s}^{-1}$ (average $40.02 \mathrm{mmol} \mathrm{m}^{-2} \mathrm{~s}^{-1}$ ). Genotypes G8, G13, and G14 were distinct from other genotypes as the best lines, with a high stomatal conductance under drought conditions. 
Table 3. Mean values for agronomic and morpho-physiological traits under control and drought conditions in 17 durum wheat genotypes across two years.

\begin{tabular}{|c|c|c|c|c|c|c|c|c|c|c|c|c|c|c|c|c|c|}
\hline Conditions & Genotype & DM & DH & GFP & PL & PE & FL & SL & NSPP & NGPS & TGW & $\mathrm{GY}\left(\mathrm{g} / \mathrm{m}^{2}\right)$ & $\operatorname{Bio}\left(\mathrm{g} / \mathrm{m}^{2}\right)$ & $\mathrm{HI}$ & $F v / F m$ & SC & $\mathrm{CT}$ \\
\hline \multirow{19}{*}{$\begin{array}{l}\text { Control } \\
\text { condition }\end{array}$} & G1 & 218 & 173 & 45 & 27.08 & 10.20 & 12.95 & 6.47 & 592 & 46 & 43.18 & 873.68 & 1968.15 & 45.29 & 0.75 & 43.30 & 33.74 \\
\hline & $\mathrm{G} 2$ & 216 & 171 & 44 & 32.56 & 13.64 & 16.36 & 6.97 & 530 & 30 & 45.28 & 463.77 & 1254.92 & 36.33 & 0.76 & 46.66 & 33.42 \\
\hline & G3 & 214 & 172 & 42 & 30.75 & 12.78 & 13.39 & 9.45 & 896 & 24 & 44.25 & 672.87 & 1554.75 & 42.70 & 0.74 & 24.99 & 34.07 \\
\hline & G4 & 217 & 175 & 42 & 24.47 & 7.75 & 13.61 & 6.70 & 432 & 43 & 43.85 & 645.57 & 1615.03 & 41.40 & 0.75 & 42.13 & 33.91 \\
\hline & G5 & 218 & 176 & 41 & 27.20 & 9.14 & 17.97 & 7.39 & 450 & 46 & 40.70 & 622.35 & 1729.28 & 36.98 & 0.76 & 46.03 & 32.76 \\
\hline & G6 & 216 & 173 & 42 & 27.14 & 10.75 & 13.39 & 6.36 & 447 & 44 & 39.30 & 565.03 & 1434.52 & 39.70 & 0.71 & 28.52 & 33.89 \\
\hline & G7 & 218 & 170 & 47 & 32.64 & 15.69 & 14.61 & 7.56 & 591 & 46 & 41.93 & 675.25 & 1623.33 & 41.95 & 0.74 & 32.61 & 32.46 \\
\hline & G8 & 215 & 173 & 42 & 32.72 & 15.89 & 13.72 & 7.53 & 603 & 41 & 42.62 & 663.45 & 1585.53 & 42.26 & 0.72 & 45.65 & 33.95 \\
\hline & G9 & 218 & 172 & 45 & 30.31 & 13.67 & 16.00 & 6.67 & 537 & 45 & 45.33 & 711.72 & 1617.92 & 44.65 & 0.67 & 34.87 & 34.63 \\
\hline & G10 & 217 & 170 & 47 & 29.92 & 13.69 & 14.94 & 6.11 & 644 & 43 & 44.91 & 887.90 & 1918.52 & 46.32 & 0.72 & 53.88 & 33.43 \\
\hline & G11 & 217 & 174 & 43 & 28.17 & 11.67 & 14.94 & 6.08 & 548 & 44 & 45.42 & 732.38 & 1653.67 & 44.54 & 0.75 & 36.26 & 33.87 \\
\hline & G12 & 217 & 170 & 47 & 26.06 & 10.81 & 16.20 & 6.39 & 56 & 49 & 42.72 & 817.67 & 1925.12 & 42.93 & 0.76 & 39.67 & 32.76 \\
\hline & G13 & 218 & 170 & 47 & 27.06 & 10.53 & 16.06 & 6.56 & 567 & 40 & 44.78 & 663.80 & 1597.25 & 42.13 & 0.77 & 49.69 & 32.56 \\
\hline & G14 & 217 & 173 & 44 & 30.81 & 13.95 & 15.36 & 7.22 & 668 & 42 & 41.98 & 862.75 & 1955.50 & 44.69 & 0.76 & 44.64 & 32.69 \\
\hline & G15 & 218 & 174 & 44 & 31.33 & 14.45 & 16.53 & 7.20 & 486 & 40 & 44.98 & 742.03 & 1734.97 & 42.81 & 0.78 & 37.67 & 33.11 \\
\hline & G16 & 218 & 170 & 47 & 33.28 & 16.25 & 14.95 & 6.39 & 667 & 47 & 45.72 & 888.57 & 1996.20 & 44.21 & 0.73 & 40.89 & 33.15 \\
\hline & G17 & 219 & 174 & 44 & 30.42 & 13.00 & 16.22 & 6.92 & 544 & 47 & 45.44 & 771.25 & 1678.73 & 45.41 & 0.74 & 53.93 & 32.91 \\
\hline & $\begin{array}{c}\text { LSD } \\
(0.05)\end{array}$ & 1.13 & 2.69 & 2.93 & 6.92 & - & 2.89 & 1.37 & 19.64 & 3.93 & - & 99.53 & 191.69 & 6.65 & - & - & - \\
\hline & $\begin{array}{l}\text { LSD } \\
(0.01)\end{array}$ & 1.51 & 3.57 & 3.89 & 9.20 & - & 3.84 & 1.82 & 26.13 & 5.22 & - & 132.37 & 254.94 & 8.85 & - & - & - \\
\hline \multirow{17}{*}{$\begin{array}{l}\text { Drought } \\
\text { condition }\end{array}$} & G1 & 214 & 175 & 39 & 23.50 & 7.02 & 16.31 & 6.91 & 472 & 35 & 25.18 & 546.63 & 1501.47 & 37.00 & 0.72 & 38.95 & 40.55 \\
\hline & G2 & 213 & 176 & 37 & 24.47 & 9.25 & 16.49 & 7.22 & 532 & 24 & 25.42 & 466.30 & 1396.67 & 30.26 & 0.77 & 35.08 & 38.47 \\
\hline & G3 & 214 & 179 & 36 & 23.03 & 6.92 & 12.69 & 8.00 & 628 & 19 & 22.99 & 486.15 & 1398.95 & 32.66 & 0.78 & 25.79 & 40.80 \\
\hline & G4 & 214 & 179 & 35 & 21.94 & 6.06 & 13.70 & 6.37 & 391 & 33 & 27.47 & 430.50 & 1267.92 & 33.10 & 0.79 & 27.70 & 40.09 \\
\hline & G5 & 218 & 179 & 38 & 16.86 & 3.97 & 16.47 & 7.35 & 297 & 29 & 19.06 & 356.17 & 1227.82 & 27.75 & 0.80 & 42.94 & 40.58 \\
\hline & G6 & 216 & 174 & 41 & 26.53 & 9.39 & 15.15 & 6.83 & 463 & 24 & 27.61 & 500.62 & 1484.22 & 35.88 & 0.74 & 42.25 & 39.55 \\
\hline & G7 & 214 & 174 & 40 & 23.00 & 9.11 & 13.55 & 7.39 & 513 & 34 & 24.57 & 485.77 & 1471.17 & 33.46 & 0.76 & 37.19 & 40.85 \\
\hline & G8 & 215 & 174 & 41 & 24.03 & 10.72 & 13.33 & 7.50 & 528 & 33 & 22.18 & 481.48 & 1490.62 & 32.83 & 0.76 & 58.19 & 40.70 \\
\hline & G9 & 214 & 176 & 38 & 23.69 & 9.30 & 16.14 & 6.50 & 463 & 30 & 20.93 & 518.60 & 1449.02 & 35.46 & 0.78 & 39.59 & 40.24 \\
\hline & G10 & 217 & 176 & 41 & 25.22 & 9.50 & 16.36 & 6.03 & 527 & 34 & 24.76 & 482.88 & 1492.25 & 32.59 & 0.77 & 32.29 & 40.78 \\
\hline & G11 & 214 & 176 & 37 & 23.08 & 7.56 & 15.17 & 6.81 & 449 & 33 & 21.89 & 477.90 & 1356.65 & 34.85 & 0.78 & 41.64 & 40.52 \\
\hline & G12 & 214 & 176 & 38 & 26.22 & 9.39 & 15.44 & 6.39 & 462 & 32 & 25.34 & 513.08 & 1539.08 & 33.91 & 0.75 & 40.53 & 40.55 \\
\hline & G13 & 215 & 175 & 39 & 25.33 & 9.33 & 16.94 & 6.97 & 403 & 35 & 24.29 & 387.62 & 1240.62 & 31.85 & 0.76 & 47.66 & 40.43 \\
\hline & G14 & 215 & 178 & 37 & 26.14 & 9.21 & 16.02 & 7.45 & 396 & 35 & 25.16 & 384.60 & 1295.82 & 30.89 & 0.74 & 44.82 & 40.12 \\
\hline & G15 & 216 & 176 & 40 & 22.06 & 7.70 & 15.36 & 6.95 & 397 & 29 & 22.85 & 399.22 & 1303.02 & 32.55 & 0.75 & 43.01 & 40.88 \\
\hline & G16 & 214 & 176 & 38 & 24.20 & 9.53 & 15.45 & 6.61 & 422 & 32 & 24.45 & 443.23 & 1278.68 & 35.26 & 0.78 & 38.10 & 39.45 \\
\hline & G17 & 214 & 175 & 39 & 26.08 & 11.83 & 16.28 & 6.61 & 433 & 31 & 24.70 & 425.23 & 1172.57 & 37.36 & 0.80 & 44.55 & 40.26 \\
\hline
\end{tabular}


Table 3. Cont

\begin{tabular}{|c|c|c|c|c|c|c|c|c|c|c|c|c|c|c|c|c|c|}
\hline Conditions & Genotype & $\mathrm{DM}$ & DH & GFP & PL & PE & FL & SL & NSPP & NGPS & TGW & GY $\left(\mathrm{g} / \mathrm{m}^{2}\right)$ & Bio $\left(\mathrm{g} / \mathrm{m}^{2}\right)$ & HI & $F v / F m$ & SC & CT \\
\hline & $\operatorname{LSD}(0.05)$ & 2.13 & 1.53 & 2.54 & - & 5.54 & 3.92 & 1.37 & 195.10 & 11.66 & 12.27 & 58.63 & - & - & - & 17.44 & - \\
\hline & LSD (0.01) & 2.83 & 2.03 & 3.37 & - & 7.37 & 5.21 & 1.82 & 259.48 & 15.51 & 16.33 & 77.98 & - & - & - & 23.19 & - \\
\hline & Control & 217.57 & 172.75 & 44.82 & 29.52 & 12.57 & 15.13 & 6.93 & 576.22 & 42.27 & 43.67 & 721.17 & 1696.67 & 42.60 & 0.74 & 41.25 & 33.37 \\
\hline & Stress & 214.88 & 176.29 & 38.58 & 23.84 & 8.57 & 15.34 & 6.93 & 457.52 & 31.19 & 24.05 & 457.99 & 1374.50 & 33.39 & 0.76 & 40.01 & 40.28 \\
\hline & $\begin{array}{l}\text { Relative } \\
\text { change }^{+}\end{array}$ & 1.24 & -2.05 & 13.91 & 19.23 & 31.83 & -1.42 & 0.06 & 20.60 & 26.21 & 44.93 & 36.49 & 18.99 & 21.62 & -3.56 & 3.01 & -20.71 \\
\hline
\end{tabular}

DH: days to heading; DM: days to maturity; GFP: grain filling period; PL: plant height (cm); PE: peduncle length (cm); FL: flag leaf length (cm); SL: spike length (cm); NSPP: number of spike per plot; NGPS: number of grains per spike; TGW: thousand grains weight (g); GY: grain yield (g plot ${ }^{-1}$ ); Bio: biomass $\left(\mathrm{g} \mathrm{plot}^{-1}\right)$; HI: harvest index; Fv/Fm: maximum quantum yield of PSII; SC: stomatal conductance $\left(\mathrm{mmol} \mathrm{m}^{-2} \mathrm{~s}^{-1}\right)$; CT: canopy temperature $\left({ }^{\circ} \mathrm{C}\right) .{ }^{+}$Negative numbers indicate value higher than the control. 


\subsection{Association Among Measured Traits}

To visualize the effects of drought stress on the relationships among the measured traits, we used two heatmaps based on Pearson's correlation coefficients among grain yield and physiological and agro-morphological traits in both control and drought conditions. Under the control condition, GY showed a positive and significant correlation with DH, GFP, CT, NGPS, and Bio. The association pattern between Bio and other traits was similar to GY. NGPS showed a positive and significant correlation with $\mathrm{DH}$ and GFP. Among the physiological traits, only CT showed a positive and significant correlation with some traits such as GY, Bio, NGPS, DH, and GFP. Other correlations between measured traits are shown in Figure 1. Under the drought condition, positive and significant correlations were found between the following parameters: GY and DH, DM, GFP, NSPP, Bio and HI; PL and PE; CT and SC, FL and SL; SC and NGPS; TGW and NGPS (Figure 1).

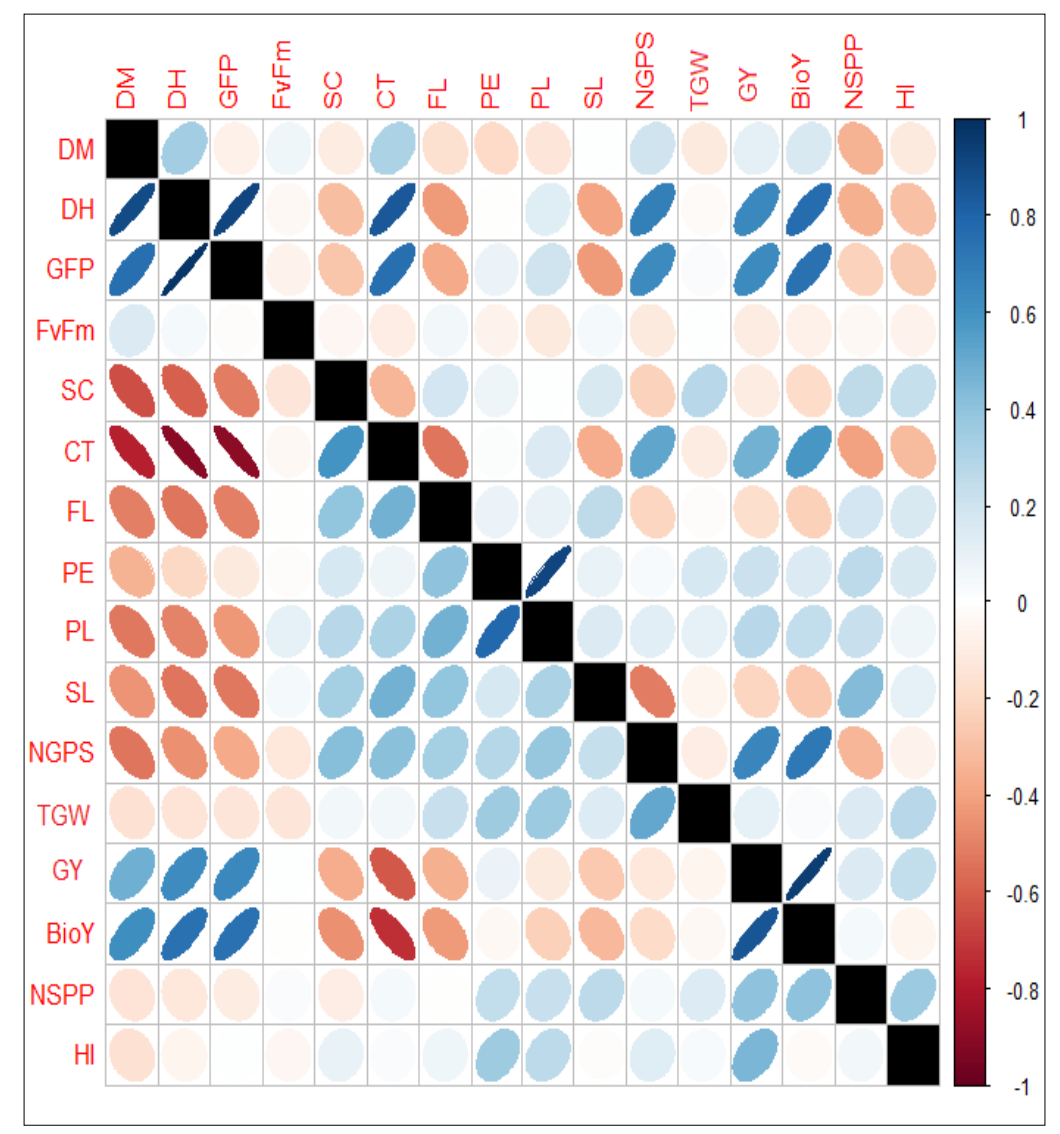

Figure 1. Heatmap indicating associations among different agronomic and morpho-physiological traits under control (upper diagonal) and drought (lower diagonal) conditions. The thickness of each ellipse indicates the correlation intensity between two traits. DH: days to heading; $\mathrm{DH}$ : days to heading; DM: days to maturity; GFP: grain filling period; PL: plant height $(\mathrm{cm})$; PE: peduncle length $(\mathrm{cm})$; FL: flag leaf length (cm); SL: spike length (cm); NSPP: number of spike per plot; NGPS: number of grains per spike; TGW: thousand grains weight (g); GY: grain yield $\left(\mathrm{g} \mathrm{plot}^{-1}\right)$; Bio: biomass $\left(\mathrm{g} \mathrm{plot}^{-1}\right)$; HI: harvest index; Fv/Fm: maximum quantum yield of PSII; SC: stomatal conductance $\left(\mathrm{mmol} \mathrm{m}^{-2} \mathrm{~s}^{-1}\right)$; CT: canopy temperature $\left({ }^{\circ} \mathrm{C}\right)$.

\subsection{Screening Drought-Tolerant Genotypes Due to Yield-Based Indices}

To identify the most tolerant genotypes, several drought tolerance and susceptibility indices were estimated. The actual values and ranking pattern for each genotype, along with the average of sum of ranks (ASR) across all indices for each genotype, are shown in Tables S1-S3. In the first year (2012-2013), genotypes G8, G9, and G10 had the lowest ASR values and highest grain yield and 
hence were distinguished from other genotypes (Table S1). In the second year (2013-2014), G1, G2, and G3 revealed the lowest ASR values and the highest grain yield under drought conditions (Table S2). Regarding the average data across both years, G1, G9, and G12 were identified as the most tolerant genotypes compared to the others (Table S3). The correlation coefficients among grain yields and the seven indices are shown in Figure 2. In all analyses, the MP, GMP, HM, and STI indices indicated a positive and significant association with Yp and Ys. Thus, these indices can be used as alternative indicators for selecting the high-yielding genotypes under drought conditions. Based on Fernandez's theory (1992), all tested genotypes were classified into four groups (A-D). Accordingly, the genotypes belonging to group A-with high yield performance under control and drought conditions-can be selected as the highest yielding and most tolerant genotypes. To illustrate the separation of the tested genotypes into each group, a three-dimensional plot based on stress tolerance index (STI) and grain yield under control and drought conditions ( $Y p$ and $Y s$, respectively) was rendered. As shown in Figure 3, the following genotypes fell in group A: G1, G7, G10, G13, G14, G15, G16, and G17 in the first year; G1 and G12 in the second year; G1, G9, G10, G11, and G12 across both years.

(A)

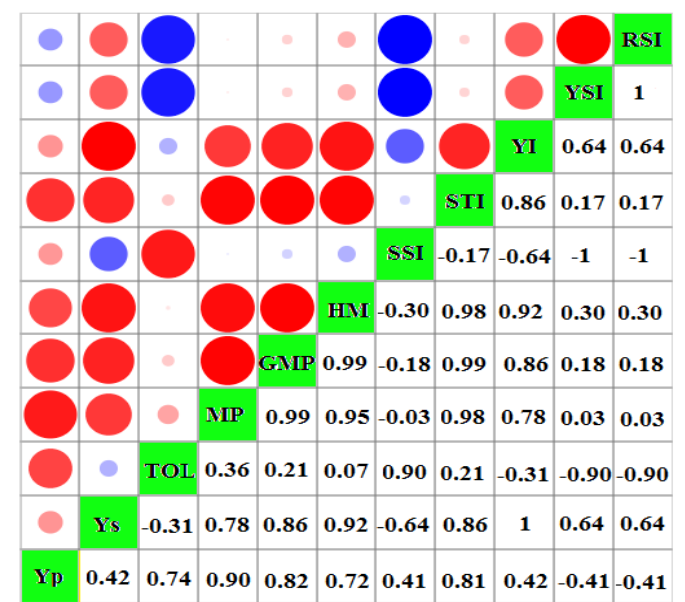

(B)

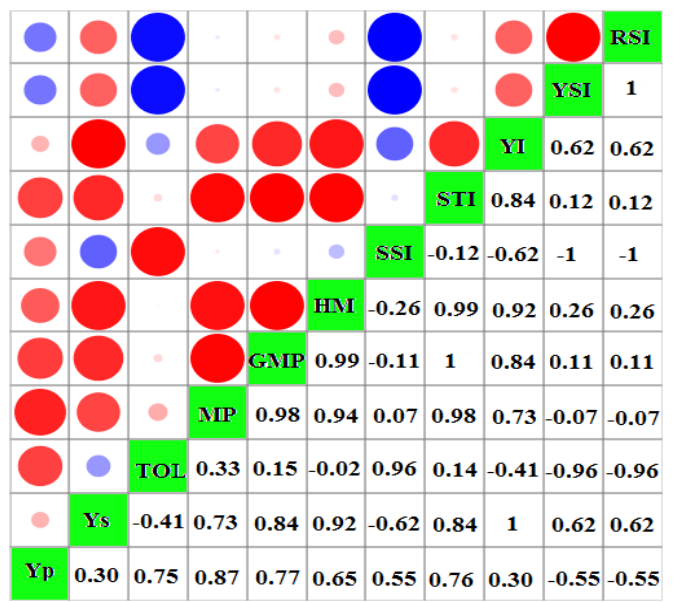

(C)

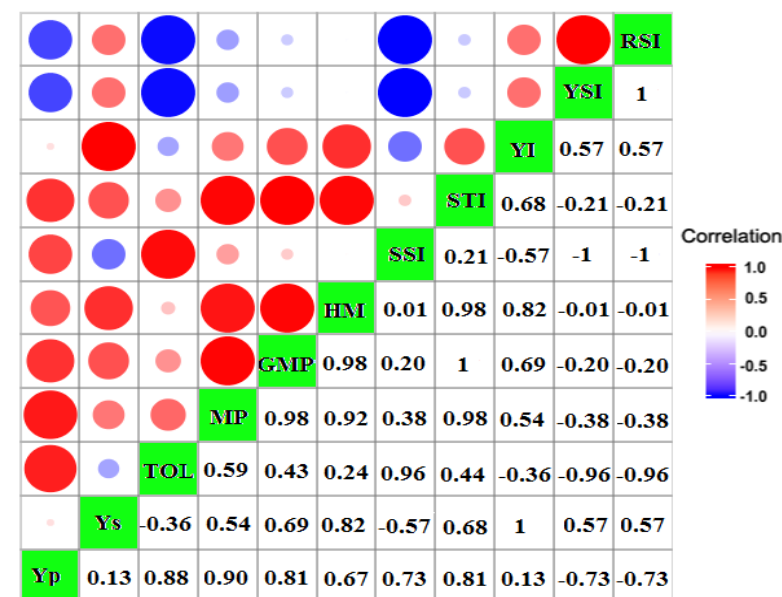

Figure 2. Heatmap indicating the association among different yield-based drought tolerance and susceptibility indices in the first year (A), second year (B), and average over two years (C). The size of each circle indicates the correlation intensity between two indices. 

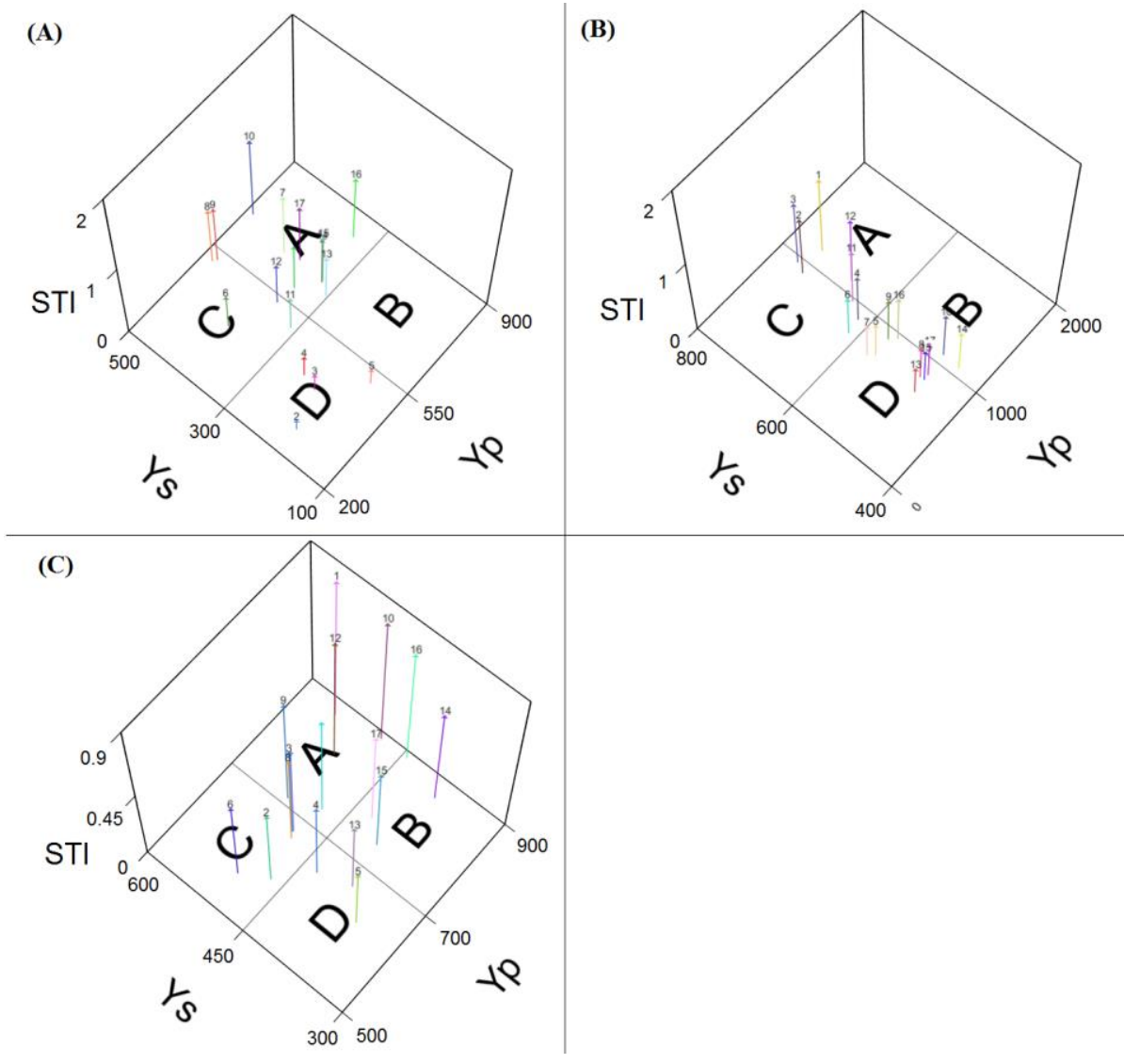

Figure 3. Three-dimensional plot rendered based on grain yield under control (Yp), grain yield under drought condition (Ys), and STI index based on data obtained in the first year (A), second year (B), and average over two years $(\mathbf{C})$.

\section{Discussion}

Among the various environmental stresses, drought is the major detrimental factor for growth and productivity [17]. The development of high-yielding cultivars with acceptable stability and adaptability across different environments is one promising strategy for improving wheat yield under drought-prone environments [18]. In general, drought stress has a negative effect on agronomic and physiological traits in wheat, regardless of the genotype and the time of stress application [19]. Among different agronomic traits, yield and its related traits are considered to be the most important components for improving wheat productivity. Indeed, grain yield can be increased through manipulation of yield-related traits such as spike length, number of spikelets per spike, and grains per spike [20]. However, several factors including pollen abortion, increased number of sterile tillers and reduction in food reserves can negatively influence the yield performance during drought stress [21]. In the present study, genotypic variation in response to drought stress was investigated in 17 durum wheat genotypes based on several phenological, morpho-physiological and agronomic traits. A significant interaction effect between stress and genotype revealed differences in how the various genotypes reacted under control and drought conditions (Table 2). Drought stress negatively affected the grain filling period, plant height, peduncle length, number of spikes per plot, number of grains per spike, thousand grains weight, grain yield, biomass and harvest index across all tested genotypes. In particular, drought stress reduced the thousand grains weight, number of grains per spike and peduncle length more than the other traits. The significant reduction in grain yield due to drought stress has also been shown in previous studies $[7,19,22]$.

Grain filling period is an important phenological trait that is associated with current photosynthesis and relocation of assimilates from reserve pools in vegetative tissues. Importantly, drought shortens the 
life cycle and duration of grain filling. Under such conditions, the grain filling period decreases due to accelerated leaf senescence, reduced photosynthesis, and sink limitations. Furthermore, the shortened grain filling period directly influences grain number and grain size, which largely accounts for the decrease in wheat yields [23]. Our results indicated that drought stress decreased the grain filling period by $\sim 14 \%$ as compared to the control condition (Table 2), suggesting substantial decrease in grain yield in the 17 durum wheat genotypes. Drought stress remarkably increased canopy temperature $(\sim 21 \%)$ compared with the control conditions (Table 2$)$. During drought periods, plants are often subjected to high temperatures. Increasing leaf temperature limits the activity of photosynthetic enzymes (such as Rubisco) leading to a reduction of carbon dioxide fixation [24]. Limitation of carbon dioxide fixation increases the rate of active oxygen formation in chloroplasts, which in turn would either manifest as oxidative damage to the plant or result in the activation of defense systems that could prevent such damage from occurring [25]. In this situation, most of the plants can adapt through the protection of their photosystem apparatus II (PSII) from photodamaging effects by dissipating the excess excitation energy thermally through down-regulating PSII [26]. The Fv/Fm parameter can be applied to determine the potential efficiency of PSII [27,28]. As shown in Table 3, drought stress increased this parameter (3.5\%) compared to the control condition (Table 1). This result indicates that some of the tested genotypes (especially G9) may have a strong capacity to protect themselves through maintenance of high levels of PSII activity. Although several studies reported that drought stress reduces $F v / F m[1,17,29]$, our results revealed that the process of energy displacement from the antenna chlorophyll complex to the PSII may not be affected by drought stress in some of the tested genotypes. The stomatal conductance (Gs) as a physiological trait has two important roles: (1) maintenance of water in leaf tissue by control of transpiration, and (2) determining the rate of gas exchange by movement of gases between the inner and outer environments of the leaf tissue. Drought stress reduces Gs and the reaction centers in PSII, as well as exposure of excess energy in the chloroplasts. All of these events restrict photosynthesis [30]. Our results revealed that although Gs was reduced by drought stress ( $\sim 3 \%$ compared to the control conditions) across all tested genotypes, some of the genotypes nevertheless showed high stomatal conductivity compared to the control. Indeed, this result confirms that some of the genotypes have a protected photosynthesis apparatus and can maintain the health of photosynthesis mechanisms under drought conditions.

The efficiency of breeding programs in diverse environments can be improved by gaining an understanding of the associations between grain yield and different selection indices. Although many agronomic, morphological, and physiological traits have been studied for their use in breeding programs for drought tolerance, only a few traits are currently recommended for application in practical programs. For instance, several traits such as stay-green character [31], canopy temperature and spike fertility [32], number of grains per plot [33], stomatal conductance and relative chlorophyll content [17,29], water use efficiency [34], root architecture [35], chlorophyll fluorescence [17,29,36] were used as selection indicators due to their correlations with grain yield under drought conditions. In the present study, a positive correlation between grain yield and other phenological characteristics (number of days to spike heading, physiological maturity, and grain filling period), as well as number of spikes per plant, biomass, and harvest index under drought conditions were found. Furthermore, negative significant correlations were observed between grain yield and canopy temperature, flag leaf, and plant height. Altogether this suggests that it is relatively easy to develop high-yielding durum genotypes with increasing numbers of spike and phonological characters-especially grain filling period-as well as decreased plant stature, canopy temperature, and flag leaf length. There was no significant correlation between yield and $F v / F m$, thousand grains weight, and peduncle length, which indicates that grain yield can potentially be improved without changing these traits under drought stress conditions (Figure 1).

Following Fernandez's theory [37], the genotypes formed four distinct groups according to their yield response to stress conditions. The first group (A) contains the genotypes with relatively equal yield in both control and stress conditions. The second group (B) includes the genotypes that show a 
high yield performance only in the control condition. The genotypes that have a high yield performance in stress conditions are classified as the third group (C), and finally the fourth group (D) includes the genotypes with low yield performance in both conditions. Based on these results, several yield-based stress tolerance and susceptibility indices have been applied to detect the tolerant genotypes. In the present study, seven drought tolerance and susceptibility indices were calculated based on grain yields under control and drought conditions. According to all analyses for each year separately as well as the average of both years, significant and positive associations between grain yields with STI, HM, MP, and GMP were found (Figure S1). This result reveals the capacity of these indices to identify genotypes with high potential yield and tolerance to drought conditions (Group A). Likewise, the ability to separate Group A genotypes from the others using these indices is consistent with the findings reported for canola [38], chickpea [39], maize [40], and durum wheat [22]. Among the yield-based indices, STI is a suitable index for characterization of the most tolerant to drought stress. Indeed, its applicability has been confirmed in numerous studies $[1,17,22,29,35,38,41,42]$. Based on the three-dimensional plots, several different genotypes were distributed in Group A each year (Figure S2). However, the genotype G1 showed the same response in all plots. To better understand the responses of the tested durum wheat genotypes and identify the most drought-tolerant genotypes, the average of the sum of ranks (ASR) across all indices was used. Based on this data, three genotypes (G1, G9, and G12) with high yield performance $\left(546.63,518.60\right.$, and $513.08 \mathrm{~g} \mathrm{plot}^{-1}$, respectively) indicated low ASR values; hence, these genotypes can be recommended as the drought-tolerant genotypes. In contrast, G5, G13, and G14 with low yield performance (356.17, 387.62, and 384.60, $\mathrm{g} \mathrm{plot}^{-1}$, respectively) revealed high ASR values, which indicated their susceptibility to drought stress. Among all genotypes, G12 as a new breeding line reveals good performance under both conditions $\left(817.67 \mathrm{~g} \mathrm{plot}^{-1}\right.$ under control, and $513.08 \mathrm{~g} \mathrm{plot}^{-1}$ under drought conditions), similar to the check variety (G1). Therefore, it can be recommended for cultivation under rainfed conditions in the arid and semi-arid regions of Iran and similar climates.

\section{Conclusions}

To summarize, our results revealed that durum wheat genotypes were significantly affected by drought stress for grain yield and several agronomic and morpho-physiological traits. This resulted in considerable variation in the measured traits and drought tolerance in these genotypes that should be considered for durum wheat breeding programs. As seen in this study, positive associations of number of grains per spike and phenological characters with grain yield make it possible to evaluate genotypes with high yield performance by using these character attributes in rainfed conditions. Among the tested genotypes, G12 as a new breeding line responded well to drought stress. It can thus be used for cultivation in drought-prone environments and to develop drought-tolerant varieties.

Supplementary Materials: The following are available online at http://www.mdpi.com/2071-1050/12/14/5610/s1, Table S1. Yield performance of 17 durum wheat genotypes under control (Yp) and drought stress (Ys) conditions, along with the yield-based drought tolerance and susceptibility indices in the first year (2011-2012); Table S2. Yield performance of 17 durum wheat genotypes under control (Yp) and drought stress (Ys) conditions, along with the yield-based drought tolerance and susceptibility indices in the second year (2012-2013); Table S3. Yield performance of 17 durum wheat genotypes under control (Yp) and drought stress (Ys) conditions, along with the yield-based drought tolerance and susceptibility indices over both years (2011-2013).

Author Contributions: Conceptualization, R.M.; methodology, R.M.; software, A.P.-A., and N.M.-T.; validation, A.P.-A., L.S., and A.E.; formal analysis, A.P.-A.; investigation, R.M., and L.S.; resources, R.M.; data curation, A.P.-A., A.E.; writing - original draft preparation, A.P.-A.; writing-review and editing, N.M.-T. and P.P.; visualization, A.E.; supervision, R.M.; project administration, R.M.; funding acquisition, R.M. All authors have read and agreed to the published version of the manuscript.

Funding: This research received no external funding.

Acknowledgments: Open access funding provided by University of Helsinki.

Conflicts of Interest: The authors declare no conflict of interest. 


\section{References}

1. Ahmed, H.G.M.D.; Sajjad, M.; Li, M.; Azmat, M.A.; Rizwan, M.; Maqsood, R.H.; Khan, S.H. Selection criteria for drought-tolerant bread wheat genotypes at seedling stage. Sustainability 2019, 11, 2584. [CrossRef]

2. Boukid, F.; Dall'Asta, M.; Bresciani, L.; Mena, P.; Del Rio, D. Phenolic profile and antioxidant capacity of landraces, old and modern Tunisian durum wheat. Eur. Food Res. Technol. 2019, 245, 73. [CrossRef]

3. Bassi, F.; Sanchez-Garcia, M. Adaptation and stability analysis of ICARDA durum wheat elites across 18 countries. Crop Sci. 2017, 57, 2419-2430. [CrossRef]

4. Loss, S.P.; Siddique, K.H.M. Morphological and physiological traits associated with wheat yield increases in mediterranean environments. In Advances in Agronomy; Sparks, D.L., Ed.; Academic Press: San Diego, CA, USA, 1994; pp. 229-276.

5. Ahmadi, J.; Pour-Aboughadareh, A.; Fabriki Ourang, S.; Mehrabi, A.A.; Siddique, K.H.M. Wild relatives of wheat: Aegilops-Triticum accessions disclose differential antioxidative and physiological responses to water stress. Acta Physiol. Plant. 2018, 40, 90. [CrossRef]

6. Siddique, K.H.M.; Kirby, E.J.M.; Perry, M.W. Ear:stem ratio in old and modern wheat varieties; relationship with improvement in number of grains per ear and yield. Field Crop Res. 1989, 21, 59-78. [CrossRef]

7. Liu, H.; Searle, L.R.; Mather, D.E.; Able, A.J.; Able, J.A. Morphological, physiological and yield responses of durum wheat to pre-anthesis water-deficit stress are genotype-dependent. Crop Pasture Sci. 2015, 66, 1024-1038. [CrossRef]

8. Araus, J.L.; Slafer, G.A.; Royo, C.; Dolores Serret, M. Breeding for yield potential and stress adaptation in cereals. Crit. Rev. Plant Sci. 2008, 27, 377-412. [CrossRef]

9. Guerrini, L.; Napoli, M.; Mancini, M.; Masella, P.; Cappelli, A.; Parenti, A.; Orlandini, S. Wheat grain composition, dough rheology and bread quality as affected by nitrogen and sulfur fertilization and seeding density. Agronomy 2020, 10, 233. [CrossRef]

10. Cappelli, A.; Oliva, N.; Cini, E. Stone milling versus roller milling: A systematic review of the effects on wheat flour quality, dough rheology, and bread characteristics. Trends Food Sci. Technol. 2020, 97, 147-155. [CrossRef]

11. Recchia, L.; Cappelli, A.; Cini, E.; Garbati Pegna, F.; Boncinelli, P. Environmental sustainability of pasta production chains: An integrated approach for comparing local and global chains. Resources 2019, 8, 56. [CrossRef]

12. Turner, N.C. Further progress in crop water relations. In Advances in Agronomy; Sparks, D.L., Ed.; Academic Press: San Diego, CA, USA, 1997; pp. 293-338.

13. Vaughan, M.M.; Block, A.; Christensen, S.A.; Allen, L.H.; Schmelz, E.A. The effects of climate change associated abiotic stresses on maize phy-tochemical defenses. Phytochem. Rev. 2018, 17, 37-49. [CrossRef]

14. SAS Institute. Base SAS 9.1 Procedures Guide; SAS Institute Inc.: Cary, NC, USA, 2011.

15. Pour-Aboughadareh, A.; Yousefian, M.; Moradkhani, H.; Moghaddam Vahed, M.; Poczai, P.; Siddique, K.H.M. iPASTIC: An online toolkit to estimate plant abiotic stress indices. Appl. Plant Sci. 2019, 7, e11278. [CrossRef] [PubMed]

16. Ketata, H.Y.; Yau, S.K.; Nachit, M. Relative Consistency Performance Across Environments; International Symposium on Physiology and Breeding of Winter Cereals for stressed Mediterranean Environments: Montpellier, France, 1989; pp. 391-400.

17. Pour-Aboughadareh, A.; Omidi, M.; Naghavi, M.R.; Etminan, A.; Mehrabi, A.A.; Poczai, P.; Bayat, H. Effect of water deficit stress on seedling biomass and physio-chemical characteristics in different species of wheat possessing the D genome. Agronomy 2019, 9, 522. [CrossRef]

18. Pradhan, G.; Prasad, V.; Fritz, A.K.; Kirkhan, M.; Gill, B. Response of Aegilops species to drought stress during reproductive stage of development. Funct. Plant Biol. 2012, 39, 51-59. [CrossRef] [PubMed]

19. Qaseem, M.F.; Qureshi, R.; Shaheen, H. Heat and their combination on the growth, yield and physiology of diverse wheat (Triticum aestivum L.) genotypes varying in sensitivity to heat and drought stress. Sci. Rep. 2019, 9, 6955. [CrossRef] [PubMed]

20. Gaju, O.; Reynolds, M.; Sparkes, D.; Foulkes, M. Relationships between large-spike phenotype, grain number, and yield potential in spring wheat. Crop Sci. 2009, 49, 961-973. [CrossRef]

21. Barnabas, B.; Jaeger, K.; Feher, A. The effect of drought and heat stress on reproductive processes in cereals. Plant. Cell. Environ. 2008, 31, 11-38. [CrossRef]

22. Etminan, A.; Pour-Aboughadareh, A.; Mohammadi, R.; Shoshtari, L.; Yousefiazarkhanian, M.; Moradkhani, H. Determining the best drought tolerance indices using artificial neural network (ANN): Insight into application of intelligent agriculture in agronomy and plant breeding. Cereal Res. Commun. 2019, 47, 170-181. [CrossRef] 
23. Dolferus, R.; Ji, X.; Richards, R.A. Abiotic stress and control of grain number in cereals. Plant Sci. 2011, 181, 331-341. [CrossRef]

24. Shahenshah; Isoda, A. Effects of water stress on leaf temperature and chlorophyll fluorescence parameters in cotton and peanut. Plant Prod. Sci. 2010, 13, 269-278. [CrossRef]

25. Smirnoff, N. The role of active oxygen in the response of plants to water deficits and desiccation. New Phytol. 1993, 125, 27-58. [CrossRef]

26. Ullah, I.; Isoda, A. Adaptive responses of soybean and cotton to water stress. I. Transpiration changes in relation to stomatal area and stomatal conductance. Plant Prod. Sci. 2005, 8, 16-26.

27. Murchie, E.H.; Lawson, T. Chlorophyll fluorescence analysis: A guide to good practice and understanding some new applications. J. Exp. Bot. 2013, 64, 3983-3998. [CrossRef] [PubMed]

28. Gorbe, E.; Calatayud, A. Applications of chlorophyll fluorescence imaging technique in horticultural research: A review. Sci. Hortic. 2012, 138, 24-35. [CrossRef]

29. Pour-Aboughadareh, A.; Ahmadi, J.; Mehrabi, A.A.; Etminan, A.; Moghaddam, M.; Siddique, K.H.M. Physiological responses to drought stress in wild relatives of wheat: Implications for wheat improvement. Acta Physiol. Plant 2017, 39, 106. [CrossRef]

30. Pietragalla, J.; Pask, A.J.D. Physiological Breeding II; Pietragalla, H., Pask, A.J.D., Mullan, D., Reynold, M.P., Eds.; CIMMYT: Mexico City, Mexico, 2012; pp. 15-17.

31. Foulkes, M.J.; Sylvester-Bradley, R.; Weightman, R.; Snape, J.W. Identifying physiological traits associated with improved drought resistance in winter wheat. Field Crop Res. 2007, 103, 11-24. [CrossRef]

32. Lafitte, H.R.; Blum, A.; Atlin, G. Using secondary traits to help identify drought tolerant genotypes. In Hardy Breeding Rice for Drought-Prone Environments; Fischer, K., Lafitte, S.R., Fukai, G., Atlin, B., Eds.; IRRI: Los Baños, CA, USA, 2003; pp. 38-39.

33. Poursiahbidi, M.; Pour-Aboughadareh, A.; Tahmasebi, G.; Jasemi, S. Evaluation of genetic diversity and interrelationships of agro-morphological characters in durum wheat (Triticum durum desf.) lines using multivariate analysis. Int. J. Agric. Res. Rev. 2013, 3, 184-194.

34. Xue, Q.; Rudda, J.C.; Liua, S.; Jessupa, K.E.; Devkotaa, R.N.; Mahano, J.R. Yield determination and water use efficiency of wheat under water-limited conditions in the U.S. Southern High Plains. Crop Sci. 2013, 54, 34-47. [CrossRef]

35. Ahmadi, J.; Pour-Aboughadareh, A.; Fabriki Ourang, S.; Mehrabi, A.A.; Siddique, K.H.M. Screening wheat germplasm for seedling root architectural traits under contrasting water regimes: Potential sources of variability for drought adaptation. Arch. Agron. Soil Sci. 2018, 64, 1351-1365. [CrossRef]

36. Sharma, D.K.; Andersen, S.B.; Ottosen, C.O.; Rosenqvist, E. Wheat cultivars selected for high Fv/Fm under heat stress maintain high photosynthesis, total chlorophyll, stomatal conductance, transpiration and dry matter. Physiol. Plant. 2015, 153, 284-298. [CrossRef]

37. Fernandez, G.C.J. Effective selection criteria for assessing plant stress tolerance. In Proceedings of the AFCTWS Adaptation of Food Crops to Temperature and Water Stress, Shanhua, Taiwan, 13-18 August 1992; pp. 257-270.

38. Khalili, M.; Naghavi, M.R.; Pour-Aboughadareh, A.; Talebzadeh, J. Evaluating of drought stress tolerance based on selection indices in spring canola cultivars (Brassica napus L.). J. Agric. Sci. 2012, 4, 78-85. [CrossRef]

39. Pour-Siahbidi, M.M.; Pour-Aboughadareh, A. Evaluation of grain yield and repeatability of drought tolerance indices for screening chickpea (Cicer aritinum L.) genotypes under rainfed conditions. Iran. J. Genet. Plant Breed. 2013, 2, 28-37.

40. Naghavi, M.R.; Pour-Aboughadareh, A.R.; Khalili, M. Evaluation of drought tolerance indices for screening some of corn (Zea mays L.) Cultivars under environmental conditions. Not. Sci. Biol. 2013, 5, 388-393. [CrossRef]

41. Saba, S.; Moghaddam, M.; Ghassemi, K.; Nishabouri, M.R. Genetic properties of drought resistance indices. J. Agric. Sci. Tech. 2001, 4, 43-49.

42. Pour-Aboughadareh, A.; Etminan, A.; Abdelrahman, M.; Siddique, K.H.M.; Tran, L.S.P. Assessment of biochemical and physiological parameters of durum wheat genotypes at the seedling stage during polyethylene glycol-induced water stress. Plant Growth Regul. 2020. [CrossRef]

(C) 2020 by the authors. Licensee MDPI, Basel, Switzerland. This article is an open access article distributed under the terms and conditions of the Creative Commons Attribution (CC BY) license (http://creativecommons.org/licenses/by/4.0/). 